\title{
MiR-612 Suppresses the Proliferation and Migration of Breast Cancer Cells and Induces their Apoptosis Through the AKT/ERK Signaling Cascade
}

\section{Sina Taefehshokr}

Tabriz University of Medical Sciences

\section{Sahar Safaei}

Tabriz University of Medical Sciences

Amin Mahmoudpour

Tabriz University of Medical Sciences

Ehsan Mikaeili

Shiraz University

Mohammad Amini

Tabriz University of Medical Sciences

Saba Hajazimian

Tabriz University of Medical Sciences

Khalil Hajiasgharzadeh

Tabriz University of Medical Sciences

Alireza Isazadeh

Tabriz University of Medical Sciences

Reza Vaezi Astamal

Tabriz University of Medical Sciences

Nima Taefehshokr

University of Western Ontario: Western University

Nazila Fathi Maroufi

Tabriz University of Medical Sciences

Arash Khaki

Islamic Azad University Tabriz Branch

Daryoush Mohajeri

Islamic Azad University Tabriz Branch

Behzad Baradaran ( $\nabla$ baradaranb@tbzmed.ac.ir)

Tabriz University of Medical Sciences https://orcid.org/0000-0002-8642-6795 
Keywords: Breast cancer, MiR-612, Signaling pathway, Apoptosis, AKT/ERK

Posted Date: September 21st, 2021

DOI: https://doi.org/10.21203/rs.3.rs-903178/v1

License: (c) (1) This work is licensed under a Creative Commons Attribution 4.0 International License. Read Full License 


\section{Abstract}

MicroRNAs (miRs) as non-coding RNAs have been generating widespread interest in cancer diagnosis and treatment. Among the previously studied miRs, miR-612 has been addressed to have a tumor suppressor function in all types of the studied cancers except esophageal squamous cell carcinoma. Despite this interest, the exact function of miR-612 in breast cancer (BC) remains elusive. Within the framework of these criteria, we tried to study the role of miR-612 in $B C$ development. The human $B C$ cell lines, MDA-MB-231 and MDA-MB-468 were transfected with miR-612. The effects of miR-612 replacement on viability, migration, invasion, cell cycle, apoptosis, and colony formation were studied in vitro. Furthermore, the protein expression of AKT and ERK were evaluated by Western blotting analysis. The results indicated that miR-612 decreased cell viability, migration, invasion, and colony formation of BC cells. Moreover, apoptosis was augmented, and thus cell cycle arrest was induced. Also, miR-612 decreased the expression and phosphorylation of proteins of the AKT/ERK signaling pathway. We suggest that miR-612-related stimulatory effects on apoptosis and its inhibitory impacts on proliferation and migration of BC cells mediates partly by suppressing the AKT/ERK signaling pathway.

\section{Introduction}

Breast cancer (BC) is the most common cancer and among the main cause of cancer-related mortality in women with approximately 4800 new cases each day [1]. The conventional management strategies, including chemotherapy, radiotherapy, hormonal therapy, surgical interventions, and immunotherapy provide satisfactory treatment results in most BC cases [2,3]. However, the aforementioned therapies cause several types of side effects, and the lack of therapy options for patients prone to metastasis and recurrence has mitigated the rate of survival [4]. Recently, microRNAs (miRs) as non-coding RNAs have been generating widespread interest in the terms of cancer diagnosis and treatment $[5,6]$. MiRs are short, endogenous non-coding RNAs consisting of 19-22 nucleotides that have a fundamental role in the regulation of genomic sites associated with cancer via targeting the 3 '-untranslated region of mRNAs post-transcriptionally [7]. Accumulating evidence has indicated that aberrant expression of miRs prompts the development of BC. Thus, miRs are recognized as diagnostic and prognostic biomarkers [8].

Protein kinase B (AKT)/extracellular signal-regulated kinase (ERK) cascade is a significant oncogenic cascade and connected with cancer cell proliferation, migration, tumorigenesis, and cell cycle and inhibition of apoptosis in numerous cancers, including BC $[9,10]$. AKT is the major PI3K signaling pathway mediator, and ERK is the distinct substrate and downstream effector of MEK kinase at the end of the MAPK signaling cascade [10]. The recognition of the complexity and heterogeneity of the signaling network in cancer cells is important, and there are several clinical trials regarding the inhibition of AKT in patients with $B C$ [11]. This demonstrates the significance of the AKT/ERK signaling pathway in BC progression. MiR-612 has been shown to have a tumor suppressor function in all of the studied cancers except esophageal squamous cell carcinoma (ESCC), in which miR-612 is associated with ESCC invasion, metastasis, and development [12]. For the first time, Tao et al. showed that miR-612 inhibits invasion and 
metastasis cascade in hepatocellular carcinoma through targeting AKT2 [13]. Despite this interest, the exact effects of miR-612 in BC remain to be elucidated.

We hypothesize that miR-612 as a tumor suppressor may involve in several cancer-related properties such as proliferation, migration, cell cycle, and apoptosis, which could enhance malignant phenotype in $\mathrm{BC}$ cell lines. Also, the connection between these properties and the AKT/ERK signaling pathway is in our focus to investigate. Within the framework of these criteria, we studied the expression and functional role of miR-612 in BC cells. To achieve this objective, BC cells were transfected with miR-612, and thereby the impact of miR-612 on cell proliferation, migration, apoptosis, clonogenicity, cell cycle, and AKT/ERK signaling pathway was investigated. We identified that miR-612 restoration could significantly inhibit cell proliferation, migration, and clonogenicity and induce apoptosis, and arrest the cell cycle by lowering the activity of the AKT/ERK signaling cascade.

\section{Materials And Methods}

\section{Cell culture and transfection}

The human BC cell lines, MDA-MB-231 and MDA-MB-468, were obtained from Pastor Institute in Iran (Iran, Tehran) and cultured in RPMI-1640 medium, supplemented with 10\% FBS and penicillin/streptomycin mixtures. All BC cell lines were cultured in a standard humidified incubator with $5 \% \mathrm{CO}_{2}$ at $37^{\circ} \mathrm{C}$.

Subsequently, $2 \times 10^{5}$ cells were cultured into each well of 6 -well plates in an FBS and antibiotic-free medium for 24-48 $\mathrm{h}$ before transfection. Then, they washed with phosphate-buffered saline (PBS) and transfected using jetPRIME transfection reagent (PolyPlus, Strasbourg, France) with different amounts of miR-612 mimics $(60,80$, and 100 pmol) after reaching 50-70\% confluency. In brief, jetPRIME reagent and miR-612 mimics were diluted in jetPRIME dilution buffer and kept for $10 \mathrm{~min}$ at room temperature (RT). The nucleotide sequence of miR-612 mimics purchased from GenePharma Company (Shanghai, China) were: 5'-GCUGGGCAGGGCUUCUGAGCUCCUU-3'. Afterward, the mixture was added to each well that containing BC cells. Consequently, the plates were incubated for $6 \mathrm{~h}$ in a standard incubator. After $6 \mathrm{~h}$ post-transfection, we added RPMI-1640 medium containing 20 percent FBS to each well. For evaluating transfection efficiency, uptake evaluation was performed using qRT-PCR.

\section{Cell viability assay}

The cell viability was measured by MTT assay. The two human BC cell lines were seeded into a 96-well plate $\left(1.5 \times 10^{4}\right.$ cells/well) and seeded in standard condition for $24 \mathrm{~h}$. The BC cell lines were transfected with negative control miR (NC) and different amounts of miR-mimics (60, 80, and $100 \mathrm{pmol})$ using jetPRIME transfection reagent. Afterward, $150 \mu \mathrm{L}$ of complete medium and $50 \mu \mathrm{L}$ MTT solution $(2 \mathrm{mg} / \mathrm{mL}$ reagent in RPMI-1640) was substituted with the former medium and incubated in standard condition for $4 \mathrm{~h}$. Later, $50 \mu$ l Dimethyl sulfoxide (DMSO) was exchanged with a former medium and kept for $30 \mathrm{~min}$ at $37^{\circ} \mathrm{C}$. Lastly, the absorbance was measured at $570 \mathrm{~nm}$ wavelength, and cell viability was measured utilizing a microplate reader. 


\section{Wound healing assay}

The human BC cell migration was determined by a wound healing test. In brief, the human BC cell lines were cultured into 24-well plates and maintained in standard conditions for $24 \mathrm{~h}$ to reach the confluency of $70-80 \%$. Then, the center of the wells was scratched using sterile $(10-100) \mu l$ pipette tips to build a gap, and the cells were then transfected with miR-612 (100 pmol). The migratory ability of the cells was monitored by an inverted microscope (Optika, Italy) at $0,10,20$, and $30 \mathrm{~h}$. The tests were implemented in triplicate.

\section{Cell cycle analysis}

Analysis of the cell cycle progression was carried out through staining with propidium iodide ( $\mathrm{PI})$. The cells were cultured into 6 -well plates $\left(1 \times 10^{5}\right.$ cells/well) and kept overnight in a standard incubator. The BC cell lines were transfected with miR-612 (100 pmol). Later, they were washed, detached, harvested, resuspended, fixed in $70 \%$ ethanol, and kept for an additional $72 \mathrm{~h}$ at $4^{\circ} \mathrm{C}$. The cells were stained at $37^{\circ} \mathrm{C}$ for $1 \mathrm{~h}$, using $50 \mu \mathrm{g} / \mathrm{ml}$ of PI. The proportion of the cells in various cell cycle phases were assessed using a flow cytometer on the FACSCalibur system (Milteny Biotec FACS Quant 10).

\section{Colony formation assay}

The cancer-cell colonies were evaluated by colony formation test. The cells were cultured $\left(1.5 \times 10^{3}\right.$ cells/ well) into 6-well plates and incubated for $24 \mathrm{~h}$. The BC cell lines were then transfected with miR-612 (100 pmol). The culture medium was changed after $72 \mathrm{~h}$ and incubated in standard conditions for 2 weeks. Then, the colonies were fixed using paraformaldehyde (PFA) (4\%) and stained using crystal violet $(0.1 \%)$ for $24 \mathrm{~h}$. The colonies were counted and averaged utilizing inverted phase-contrast microscopy.

\section{Apoptosis assay}

The apoptosis ratio was measured by fluorescein isothiocyanate (FITC)/PI kit according to our previous study [14]. In brief, the cells were seeded $\left(1.5 \times 10^{5}\right.$ cells/well) into a 6-well plate and kept in standard condition for $24 \mathrm{~h}$. The BC cell lines were then transfected with miR-612 (100 pmol). The cells were washed with ice-cold PBS, trypsinized, centrifuged, and added to a binding buffer solution containing annexin V/PI. The cell suspension $(100 \mu \mathrm{L})$ was incubated in standard condition, darkness, and RT with PI (10 mL), Annexin V-FITC ( $5 \mathrm{~mL})$, and binding buffer $(400 \mu \mathrm{L})$ for $15 \mathrm{~min}$. Lastly, quantitative apoptosis was determined utilizing FITC/PI by flow cytometry instrument.

\section{Apoptosis analysis by 4, 6-diamidino-2-phenylindole (DAPI) staining}

To estimate the apoptosis of the cells, they were cultured into 96 -well plates $\left(15 \times 10^{3}\right.$ cells $)$ and maintained for $24 \mathrm{~h}$ at $37^{\circ} \mathrm{C}$ and then transfected with miR-612 (100 pmol). The cells were first washed with and then were fixed with PFA $4 \%$ solution (Sigma Aldrich, USA) for $48 \mathrm{~h}$ at RT. Next, the cells were permeabilized with $0.3 \%$ Triton X-100 for 10 min. Lastly, the cells after washing with PBS were stained 
with DAPI (300 ng/ml) for 10 min in dark and analyzed utilizing Cytation 5 Cell Imaging Multi-Mode Reader (BioTek, VT).

\section{Quantitative RT-PCR}

The mRNA levels of AKT, Bax, Bcl2, Caspase3, Caspase8, Cyclin D, MMP3, PTEN, and ROCK1 were evaluated using quantitative RT-PCR. The cells were cultured in 6 -well plates $\left(1 \times 10^{5} \mathrm{cells} /\right.$ well $)$ and kept for $24 \mathrm{~h}$ in a humidified incubator. The cells were then transfected with miR-612 (100 pmol). Total RNA was harvested from the cell pellets (approximately $1 \times 10^{6}$ cell) with RiboEx reagent according to our previous study [15]. The quality of the extracted RNA was measured by a NanoDrop spectrophotometer. Then, cDNA synthesis was done using mRNA Reverse Transcription Kit (Biofact, South Korea) as the manufacturer's protocol. The used primer sequences are shown in Table 1. The Real-Time PCR was carried out using $5 \mu \mathrm{L}$ Master Mix, $1 \mu \mathrm{g}$ cDNA, $0.5 \mu \mathrm{L}$ forward primer, and $0.5 \mu \mathrm{L}$ reverse primer, in $10 \mu \mathrm{L}$ total volume, as follows: one cycle for initial denaturation in $94^{\circ} \mathrm{C}$ for $1 \mathrm{~min}, 40$ cycles for denaturation in $94^{\circ} \mathrm{C}$ for $10 \mathrm{~s}, 40$ cycles for annealing for $30 \mathrm{~s}$, and 40 cycles for extension in $72^{\circ} \mathrm{C}$ for $20 \mathrm{~s}$. Also, the ACTB gene was reported as an internal control. The mRNA expression level was determined by the StepOnePlus System (Applied Biosystems, USA), and data were assessed by a comparative $2^{-\triangle \Delta C t}$ threshold cycle. 
Table 1

Sequences and characteristics of primers used for genes mRNA expression.

\begin{tabular}{|c|c|}
\hline & \\
\hline Genes & Primer sequences \\
\hline$B A X$ & 5'-GACTCCCCCCGAGAGGTCTT-3' \\
\hline & 5'-ACAGGGCCTTGAGCACCAGTT-3' \\
\hline$B C L 2$ & 5囚-CTGTGGATGACTGAGTACCTG-3】 \\
\hline & 5囚-GAGACAGCCAGGAGAAATCA-3】 \\
\hline CASPASE 3 & 5囚-CATGGAAGCGAATCAATGGACT-3囚 \\
\hline & 5】-CTGTACCAGACCGAGATGTCA - 3】 \\
\hline CASPASE 8 & 5囚-F: AGAGTCTGTGCCCAAATCAAC - 3】 \\
\hline & 5囚-GCTGCTTCTCTCTTTGCTGAA-3】 \\
\hline$A K T$ & 5囚-GCTGCACAAACGAGGGGAG-3】 \\
\hline & 5囚-CCGCTCCGTCTTCATCAGCT-3囚 \\
\hline ROCK1 & 5囚-AATCGTGTGGGATGCTACCT-3囚 \\
\hline & 5囚-AAAACCCTCAGTGTGTTGTGC-3》 \\
\hline MMP3 & 5】-CGGTTCCGCCTGTCTCAAG-3】 \\
\hline & 5》-CGCCAAAAGTGCCTGTCTT-3囚 \\
\hline PTEN & 5囚-TGATGTAGTAAGTTGTGCTGAAAGA-3】 \\
\hline & 5囚-GCACATATCATTACACCAGTTCGT-3囚 \\
\hline CYCLIN D & 5囚-TGGATGCTGGAGGTCTGCGA-3》 \\
\hline & 5囚-GTCTCCTTCATCTTAGAGGCCACG-3囚 \\
\hline GAPDH & 5囚-CAAGATCATCAGCAATGCCT-3囚 \\
\hline & 5囚-GCCATCACGCCACAGTTTCC-3囚 \\
\hline
\end{tabular}

\section{Western blot analysis}

The expression of AKT, P-AKT, ERK, and P-ERK at the protein level were analyzed using western blotting in $\mathrm{BC}$ cells. The cells were cultured in 6-well plates $\left(1 \times 10^{5}\right.$ cells/well) and kept overnight. The BC cell lines were transfected with a transfection reagent $(1.0 \mathrm{nM})$. The whole protein was isolated by RIPA lysis buffer containing protease inhibitor (Santa Cruz, CA) according to the recommended instructions. Briefly, $100 \mu \mathrm{g}$ of proteins were separated by applying 12\% SDS-PAGE electrophoresis followed by PVDF blotting (Roche Diagnostics $\mathrm{GmbH}$, Rotkreuz, Switzerland). The membrane was blocked using a $0.5 \%$ Tween 20 and then incubated with primary antibodies (1:1,000; sc-14700; Santa Cruz Biotechnology) at $4^{\circ} \mathrm{C}$ for 24 hours. The 
horseradish peroxidase (HRP) conjugated rabbit anti-goat secondary antibody (1:1,000; Santa Cruz Biotechnology) was utilized as a secondary antibody at RT for $60 \mathrm{~min}$. The protein detection was performed using ImageJ 1.63 Software (NIH, MD).

\section{Statistical analysis}

All data and values are shown as the mean \pm SEM. GraphPad Prism 6 software (San Diego, CA, USA) was applied for statistical analysis. One-way analyses of variance were done to demonstrate statistical differences among groups, followed by the Tukey test. The P values smaller than 0.05 were considered statistically significant.

\section{Results}

\section{Transfection of miR-612 reduced the cell viability of BC cell lines}

To identify the possible role of miR-612 on the cell proliferation and viability in BC cell line. The findings showed that the transfection of miR-612 could lead to the reduced viability of both BC cells (Fig. 1A), showing that restoration of miR-612 could suppress the proliferation rate BC cells. Also, no significant changes were detected between the viability of control cells and cells transfected with miR-control (NC). Furthermore, qRT-PCR results illustrated the significant upregulation of miR-612 in both two cell lines through transfection of $100 \mathrm{pmol}$ of miR-mimics (Fig. 1B), confirming the efficient restoration of miR-612.

\section{Overexpression of miR-612 inhibited migration and invasion of $\mathrm{BC}$ cell lines}

The wound-healing test showed a marked decrease in the migration of $B C$ cells following transfection of miR-612 (Fig. 2). These data suggested that miR-612 might inhibit the invasion and migration of BC cells. To elucidate the inhibitory role of miR-612 in the migration and invasion of BC cells, we evaluated mRNA expression of MMP3 and ROCK1 genes. The Real-Time PCR analysis showed a lower expression of MMP3 and ROCK1 genes in miR-612 transfected cancer cells. Our study designated a pivotal role of MMP3 and ROCK1 genes in the migratory and invasion ability of both BC cells (Fig. 3).

\section{Overexpression of miR-612 inhibited cell cycle progression of $\mathrm{BC}$ cell lines}

The cell cycle alteration was observed in BC cells after miR-612 transient transfection. The sub-G1 phase increased in transfected cancer cells with miR-612 (Fig. 4), indicating that transfection of BC cells with miR-612 led to the inhibition of the cell cycle. To investigate whether miR-612 inhibits the cell cycle in BC cells, we assessed the mRNA levels of cyclin D and PTEN genes. Cell cycle-related gene expression 
showed significantly increased expression of the PTEN gene, as well as reduced expression of cyclin D gene in transfected miR-612 BC cells (Fig. 3).

\section{Overexpression of miR-612 inhibited colony formation of $\mathrm{BC}$ cell lines}

Following miR-612 transfection, colony formation, colony diameter, and colony size of BC cells were dramatically reduced (Fig. 5). These data demonstrated that miR-612 could suppress the colony formation of BC cells.

\section{Overexpression of miR-612 suppressed BC cells apoptosis}

Apoptosis assessment by DAPI staining indicated further fragmentation and nuclear chromatin condensation in miR-612 transfected cells. This indicates that miR-612 may result in apoptosis elevation in both BC cells (Fig. 6). Moreover, apoptosis assessment by Annexin V-FITC/PI method revealed a significantly increased percentage of apoptotic cells in both early and late phases in miR-612 transfected cells. The percentage of total apoptosis in both untreated BC cells was less than $0.1 \%$, while after miR612 transfection this proportion increased to $10.6 \%$ and $17.3 \%$ in MDA-MB-231 and MDA-MB-468 cells respectively (Fig. 7).

To investigate whether miR-612 induces apoptosis in BC cells, we evaluated the mRNA levels of AKT, Bax, $\mathrm{Bcl} 2$, Caspase3, and Caspase8 genes. Apoptosis-related gene expression showed that transfection of miR-612 significantly enhanced the mRNA expression of Bax, Caspase3, and Caspase8 genes in both cells. Furthermore, mRNA expressions of the Bcl2 and AKT genes were significantly decreased (Fig. 3).

\section{Overexpression of miR-612 decreased the protein expression of AKT/ERK signaling cascade}

To evaluate whether miR-612 induces apoptosis in BC cells, we assessed the expression levels of proteins involved in the AKT/ERK signaling cascade. In the AKT/ERK signaling cascade, the findings revealed that expression levels of AKT, P-AKT, ERK, and P-ERK were reduced significantly in both investigated cell lines (Fig. 8). Our study suggested a key role of the AKT/ERK signaling cascade in the apoptosis of BC cells.

\section{Discussion}

MiRs are supported by accumulating evidence as practical biomarkers for cancer management. Many miRs in different cancers are aberrantly expressed, and the roles of certain miRs have also been described $[16,17]$. Genome-wide analysis of miRs with the MiRaGE approach designated that miR-612 was downregulated in cancer tissues comparing to non-tumorous tissues in colorectal cancer [18]. The exact physiological role of miR-612, however, was unknown, especially in cancer development. 
Our study revealed that miR-612 has inhibitory functions on cell proliferation, invasion, and migration and enhances apoptosis, and cell cycle arrest of BC cells. Also, we reported that miR-612 expression was inversely associated with $\mathrm{BC}$ cell inhibition. We designated that miR-612 significantly decreased the BC cell viability, proliferation, and colony formation ability. These data stipulate that miR-612 suppresses migration, proliferation, and invasion in BC cells, but it is not clear whether miR-612 has an antimetastatic function in other types of cancer cells. We further verified that miR-612 targets AKT/ERK signaling pathways and exerts its suppressive role on BC cells through apoptosis.

High mortality rates are related to the metastasis and invasion of the cells in patients with various cancers $[19,20]$. The wound-healing approach was used in this regard to assess the effects of miR-612 on the migration of $\mathrm{BC}$ cells. As previously mentioned, our study designated that the invasion and migration of miR-612-transfected BC cells substantially decreased compared to the control group. To further investigate the effects of miR-612 on the inhibition of migratory ability and invasion of BC cells, we evaluated the MMP3 and ROCK1 gene expression in miR-612-transfected BC cells. Previous observations revealed that MMP3 and ROCK1 played a pivotal function in cell proliferation, invasion, and metastasis of various cancer cells [21, 22]. Moreover, the MMP3 and ROCK1 genes are overexpressed in approximately all human cancers and considered as potential targets for cancer therapy [23]. The obtained data indicated that miR-612 significantly reduced the expression of MMP3 and ROCK1 in BC cells and thus inhibited the invasion and migration of BC cells.

To examine the effects of miR-612 in BC cell inhibition, the cell cycle arrest was assessed in miR-612transfected cancer cells. Sub-G1 DNA content in miR-612-transfected cells was assessed by PI staining due to involvement of the $\mathrm{G} 1 / \mathrm{G} 0$ cell cycle arrest in apoptosis. Our findings demonstrated that the miR612 considerably enhanced the number of cells in the phase G0/G1 and blocked the transition in miR-612 transfected cancer cells from phase $\mathrm{G} 1$ to $S$. This indicates the effects of miR-612 on cell cycle arrest and inhibition of BC cell proliferation, which may correlate with apoptosis. To further investigate the functions of miR-612 on the cell cycle arrest in BC cells, we evaluated the cyclin D and PTEN gene expression in miR-612-transfected cancer cells. Previous studies showed the crucial role of cyclin D and PTEN in the cell cycle and apoptosis of various cancer cells $[24,25]$. Also, the cyclin D and PTEN genes are dysregulated in approximately all human cancers. Thus, they are considered potential targets for cancer therapy [26]. The obtained results indicated that miR-612 significantly suppressed the expression of MMP3 and ROCK1 in BC cells, indicating that miR-612 may inhibit the cell cycle in BC cells.

Apoptosis induction is an important treatment mechanism in different cancer cells. In our study, the apoptosis of miR-612-transfected BC cells was investigated. The results demonstrated that after transfection with miR-612 apoptosis indices of BC cells were increased. Inconsistent with other studies, miR-612 results in the induction of apoptosis in different tumor cells [26, 27]. The family of caspases proteins plays a significant role in initiating and executing apoptosis. The proteins caspase 3 and caspase8 are the most frequently involved in apoptosis in different types of tumor cells [28]. Accordingly, we evaluated the caspase 3 and caspase 8 gene expression in miR-612-transfected cancer cells. The obtained results revealed that the miR-612 significantly increased both caspase 3 and caspase 8 gene 
expression. This suggests that miR-612 exerts satisfactory anticancer efficacy by increasing proapoptotic factors and inducing apoptosis in tumor cells. Nevertheless, underlying mechanisms of apoptosis induction by miR-612 have not been revealed. Following the transfection of miR-612, the mRNA expression of AKT and Bcl2 as anti-apoptotic genes was reduced. Additionally, Bax expression as the proapoptotic gene was augmented, indicating increased apoptosis.

Also, we assessed the protein levels involved in the AKT/ERK signaling cascade to further investigate whether miR-612 induces apoptosis in the BC cells. Early studies suggested that miR-612 could suppress the potential of hepatocellular carcinoma carcinogenesis and metastasis by targeting AKT2 [13,29]. We showed that miR-612 inhibited BC cell proliferation and migration by inhibiting the expression of the AKT/ERK signaling pathway. AKT is a serine/threonine kinase that regulates cellular functions including cell migration, proliferation, metabolism, and apoptosis [30,31]. The AKT/ERK signaling regulates the expression of associated proteins including $\mathrm{Bax}, \mathrm{Bcl} 2$, and cyclin D1, in the cell cycle and cell apoptosis $[30,31]$. The pathways PI3K/AKT and MAPK/ERK are both important cascades of intracellular signaling, regulating cell growth, proliferation, invasion, survival, mobility, and apoptosis [32, 33]. It was observed in the current study that miR-612 strongly decreased the activation of the AKT/ERK signaling cascade in BC cells. Therefore, we suggest that miR-612 induces apoptosis and suppresses proliferation and migration of $B C$ cells by suppressing the AKT/ERK signaling cascade.

\section{Declarations}

\section{Funding}

This work was financially supported by a grant from Tabriz University of Medical Sciences, Tabriz, Iran.

\section{Acknowledgements}

We thank the research staff at the Immunology Research Center, Tabriz University of Medical Sciences for assistance in this study.

\section{Conflicts of interest/Competing interests}

The authors have no conflicts of interest to declare.

\section{Availability of data and material}

The data that support the findings of this study are available from the corresponding author upon reasonable request.

\section{Authors' contributions}

ST, SS, and BB devised the main conceptual ideas and participated in the design of the work. BB provided biological materials and reagents. ST, SS, AM, EM, MA, and SH performed the experiments. KH, Al, RVA, 
NT, and NFM wrote the initial draft of the manuscript. AK, DM, and BB participated in the analysis of the work and reviewed and edited the manuscript. BB supervised the study.

\section{Ethics approval}

All experiments and procedures were conducted in compliance with the ethical principles of Tabriz University of Medical Science, Tabriz, Iran and approved by the regional ethical committee for medical research.

\section{Consent to participate}

This article does not contain any studies with human or animal subjects performed by any of the authors.

\section{Consent for publication}

All authors agree with publication.

\section{Conflict of Interest}

None

\section{References}

1. Siegel RL, Miller KD, Jemal A. Cancer statistics, 2019. CA Cancer J Clin. 2019;69:7-34.

2. Taefehshokr N, Baradaran B, Baghbanzadeh A, Taefehshokr S. Promising approaches in cancer immunotherapy. Immunobiology. 2020;225:151875.

3. Firouzi Amoodizaj F, Baghaeifar S, Taheri E, Farhoudi Sefidan Jadid M, Safi M, Seyyed Sani N, et al. Enhanced anticancer potency of doxorubicin in combination with curcumin in gastric adenocarcinoma. J Biochem Mol Toxicol. 2020;34.

4. Hajazimian S, Maleki M, Mehrabad SD, Isazadeh A. Human Wharton's jelly stem cells inhibit endometriosis through apoptosis induction. Reproduction. 2020;159:549-58.

5. Mansoori B, Mohammadi A, Shirjang S, Baradaran B. MicroRNAs in the Diagnosis and Treatment of Cancer. Immunol Invest Taylor Francis. 2017;46:880-97.

6. Ma S, Fu T, Zhao S, Gao M. MicroRNA-34a-5p suppresses tumorigenesis and progression of glioma and potentiates Temozolomide-induced cytotoxicity for glioma cells by targeting HMGA2. Eur J Pharmacol. 2019;852:42-50.

7. Khordadmehr M, Shahbazi R, Ezzati H, Jigari-Asl F, Sadreddini S, Baradaran B, et al. Key microRNAs in the biology of breast cancer; emerging evidence in the last decade. J Cell Physiol. 2019;234:831626.

8. Bertoli G, Cava C, Castiglioni I. MicroRNAs. New Biomarkers for Diagnosis, Prognosis, Therapy Prediction and Therapeutic Tools for Breast Cancer. Theranostics. 2015;5:1122-43. 
9. Hu T, Zhou R, Zhao Y, Wu G. Integrin a6/Akt/Erk signaling is essential for human breast cancer resistance to radiotherapy. Sci Rep. 2016;6:33376.

10. Saini KS, Loi S, de Azambuja E, Metzger-Filho O, Saini ML, Ignatiadis M, et al. Targeting the $\mathrm{PI3K} / \mathrm{AKT} / \mathrm{mTOR}$ and Raf/MEK/ERK pathways in the treatment of breast cancer. Cancer Treat Rev. 2013;39:935-46.

11. Xing Y, Lin NU, Maurer MA, Chen H, Mahvash A, Sahin A, et al. Phase II trial of AKT inhibitor MK-2206 in patients with advanced breast cancer who have tumors with PIK3CA or AKT mutations, and/or PTEN loss/PTEN mutation. Breast Cancer Res. 2019;21:78.

12. Zhou P, Dong H, He S, Fang L, Jiang N, Sun Q. miR612 is associated with esophageal squamous cell carcinoma development and metastasis, mediated through TP53. Mol Med Rep. 2017;16:1855-63.

13. Tao Z-H, Wan J-L, Zeng L-Y, Xie L, Sun H-C, Qin L-X, et al. miR-612 suppresses the invasive-metastatic cascade in hepatocellular carcinoma. J Exp Med. 2013;210:789-803.

14. Hajiasgharzadeh K, Somi MH, Mansoori B, Doustvandi MA, Vahidian F, Alizadeh M, et al. Alpha7 nicotinic acetylcholine receptor mediates nicotine-induced apoptosis and cell cycle arrest of hepatocellular carcinoma HepG2 cells. Adv Pharm Bull Tabriz University of Medical Sciences. 2020;10:65-71.

15. Dastmalchi N, Hosseinpourfeizi MA, Khojasteh SMB, Baradaran B, Safaralizadeh R. Tumor suppressive activity of miR-424-5p in breast cancer cells through targeting PD-L1 and modulating PTEN/PI3K/AKT/mTOR signaling pathway. Life Sci. 2020;259:118239.

16. Cheng G. Circulating miRNAs: Roles in cancer diagnosis, prognosis and therapy. Adv Drug Deliv Rev. 2015;81:75-93.

17. Soheilyfar S, Velashjerdi Z, Hajizadeh YS, Maroufi NF, Amini Z, Khorrami A, et al. In vivo and in vitro impact of miR-31 and miR-143 on the suppression of metastasis and invasion in breast cancer. $J$ BUON. 2018;23:1290-6.

18. Cummins JM, He Y, Leary RJ, Pagliarini R, Diaz LA, Sjoblom T, et al. The colorectal microRNAome. Proc Natl Acad Sci. 2006;103:3687-92.

19. Bakhshaiesh TO, Armat M, Shanehbandi D, Sharifi S, Baradaran B, Hejazi MS, et al. Arsenic Trioxide Promotes Paclitaxel Cytotoxicity in Resistant Breast Cancer Cells. Asian Pacific J Cancer Prev. 2015;16:5191-7.

20. Sun X, Huang T, Liu Z, Sun M, Luo S. LncRNA SNHG7 contributes to tumorigenesis and progression in breast cancer by interacting with miR-34a through EMT initiation and the Notch-1 pathway. Eur J Pharmacol. 2019;856:172407.

21. Maroufi NF, Vahedian V, Akbarzadeh M, Mohammadian M, Zahedi M, Isazadeh A, et al. The apatinib inhibits breast cancer cell line MDA-MB-231 in vitro by inducing apoptosis, cell cycle arrest, and regulating nuclear factor- $\mathrm{B}(\mathrm{NF}-\mathrm{KB})$ and mitogen-activated protein kinase (MAPK) signaling pathways. Breast Cancer. 2020;27:613-20.

22. Maroufi NF, Vahedian V, Hemati S, Rashidi M-R, Akbarzadeh M, Zahedi M, et al. Targeting cancer stem cells by melatonin: Effective therapy for cancer treatment. Pathol - Res Pract. 2020;216:152919. 
23. Egeblad M, Werb Z. New functions for the matrix metalloproteinases in cancer progression. Nat Rev Cancer. 2002;2:161-74.

24. Diao L, Chen Y-G. PTEN, a general negative regulator of cyclin D expression. Cell Res. 2007;17:2912.

25. Radu A, Neubauer V, Akagi T, Hanafusa H, Georgescu M-M. PTEN Induces Cell Cycle Arrest by Decreasing the Level and Nuclear Localization of Cyclin D1. Mol Cell Biol. 2003;23:6139-49.

26. Brandmaier A, Hou S-Q, Shen WH. Cell Cycle Control by PTEN. J Mol Biol. 2017;429:2265-77.

27. Sui $X$, Chen $R$, Wang Z, Huang Z, Kong N, Zhang M, et al. Autophagy and chemotherapy resistance: a promising therapeutic target for cancer treatment. Cell Death Dis. 2013;4:e838-8.

28. Pfeffer CMSA. Apoptosis. A Target for Anticancer Therapy. Int J Mol Sci. 2018;19:448.

29. Tang J, Tao Z-H, Wen D, Wan J-L, Liu D-L, Zhang S, et al. miR-612 suppresses the stemness of liver cancer via Wnt/ $\beta$-catenin signaling. Biochem Biophys Res Commun Elsevier. 2014;447:210-5.

30. Agarwal E, Brattain MG, Chowdhury S. Cell survival and metastasis regulation by Akt signaling in colorectal cancer. Cell Signal. 2013;25:1711-9.

31. Kang B, Hao C, Wang H, Zhang J, Xing R, Shao J, et al. Evaluation of Hepatic-Metastasis Risk of Colorectal Cancer upon the Protein Signature of PI3K/AKT Pathway. J Proteome Res. 2008;7:350715.

32. McCubrey JA, Steelman LS, Chappell WH, Abrams SL, Wong EWT, Chang F, et al. Roles of the Raf/MEK/ERK pathway in cell growth, malignant transformation and drug resistance. Biochim Biophys Acta - Mol Cell Res. 2007;1773:1263-84.

33. Manning BD, Toker A. AKT/PKB Signaling: Navigating the Network. Cell. 2017;169:381-405.

\section{Figures}



A

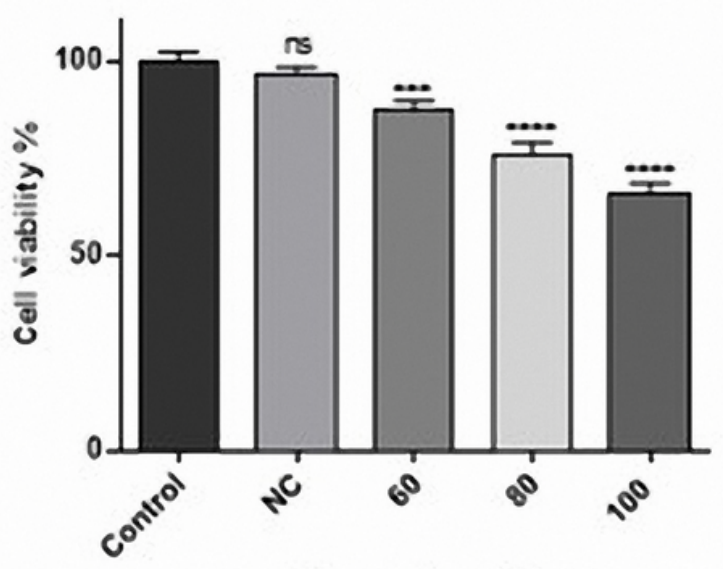

Amount (pmol)

B

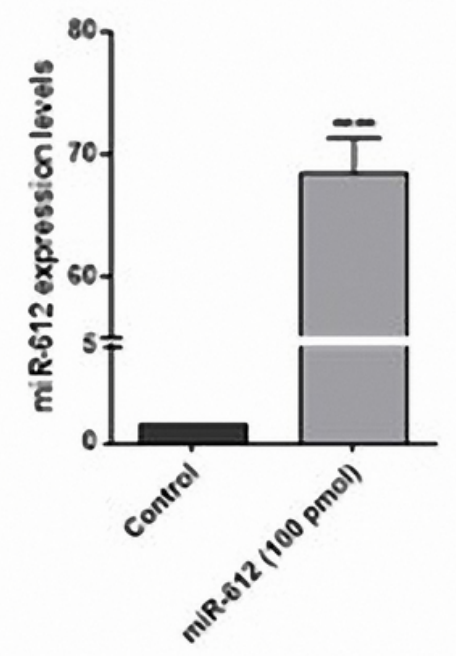

MDA-MB-468

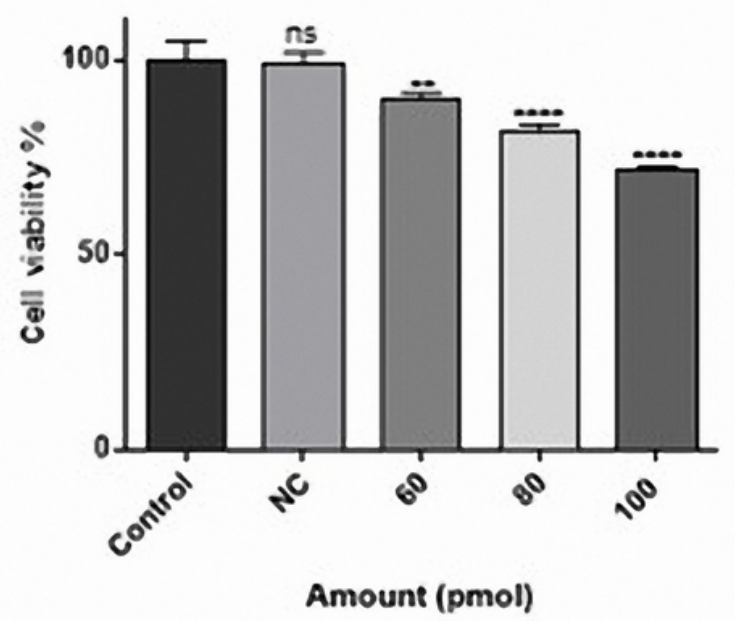

MDA-MB-468

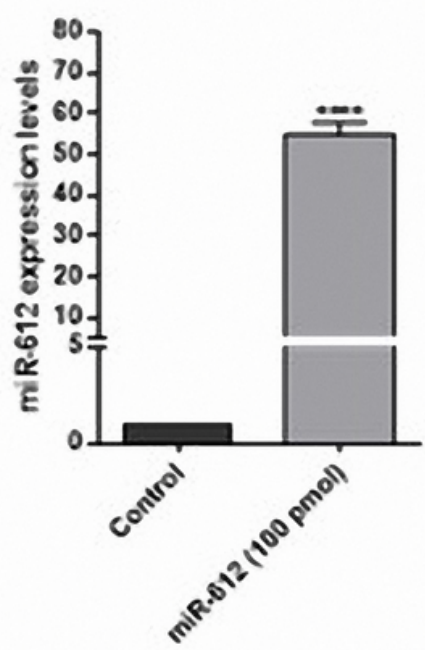

Figure 1

(A) The viability of MDA-MB-231 and MDA-MB-468 breast cancer cells transfected with miR-612. (B) Quantification comparing miR-612 expression levels in transfected and control MDA-MB-231 and MDAMB-468 cells. ${ }^{* \star} p<0.01,{ }^{* \star *} p<0.001,{ }^{* \star \star *} p<0.0001$ 


\section{MDA-MB-231}

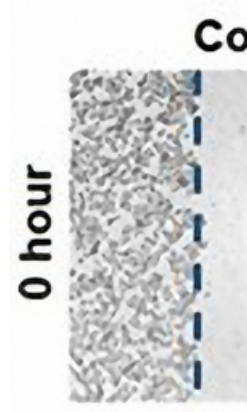

ol
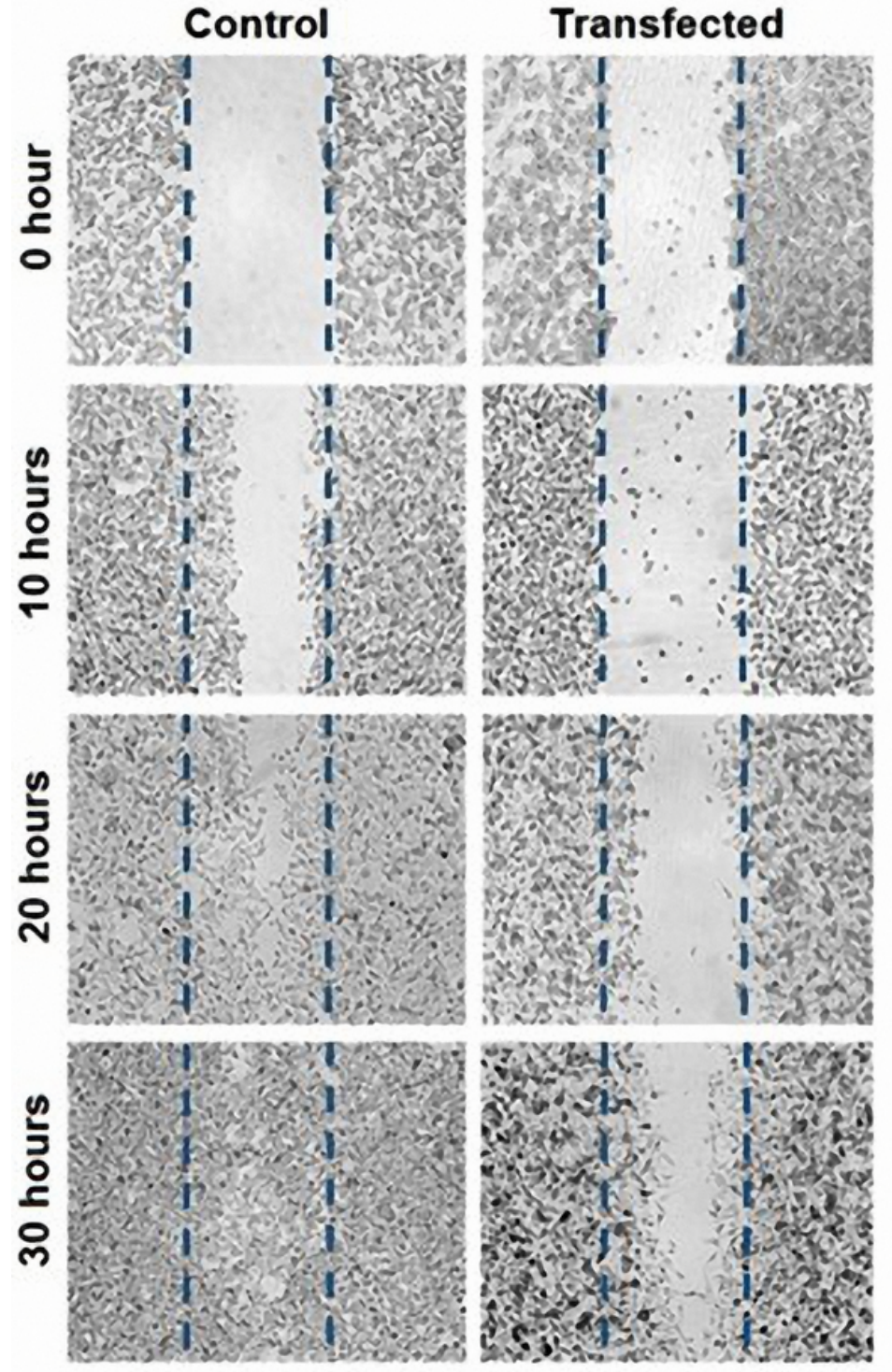

\section{MDA-MB-468}

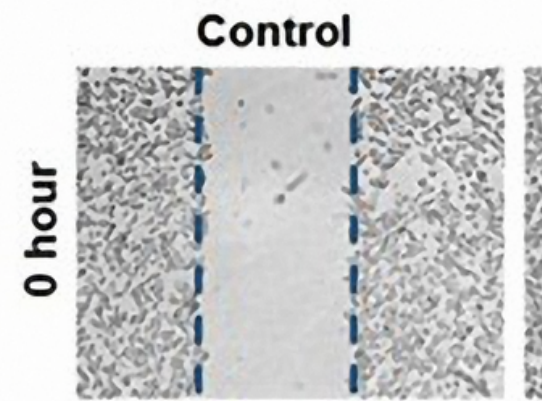

Transfected
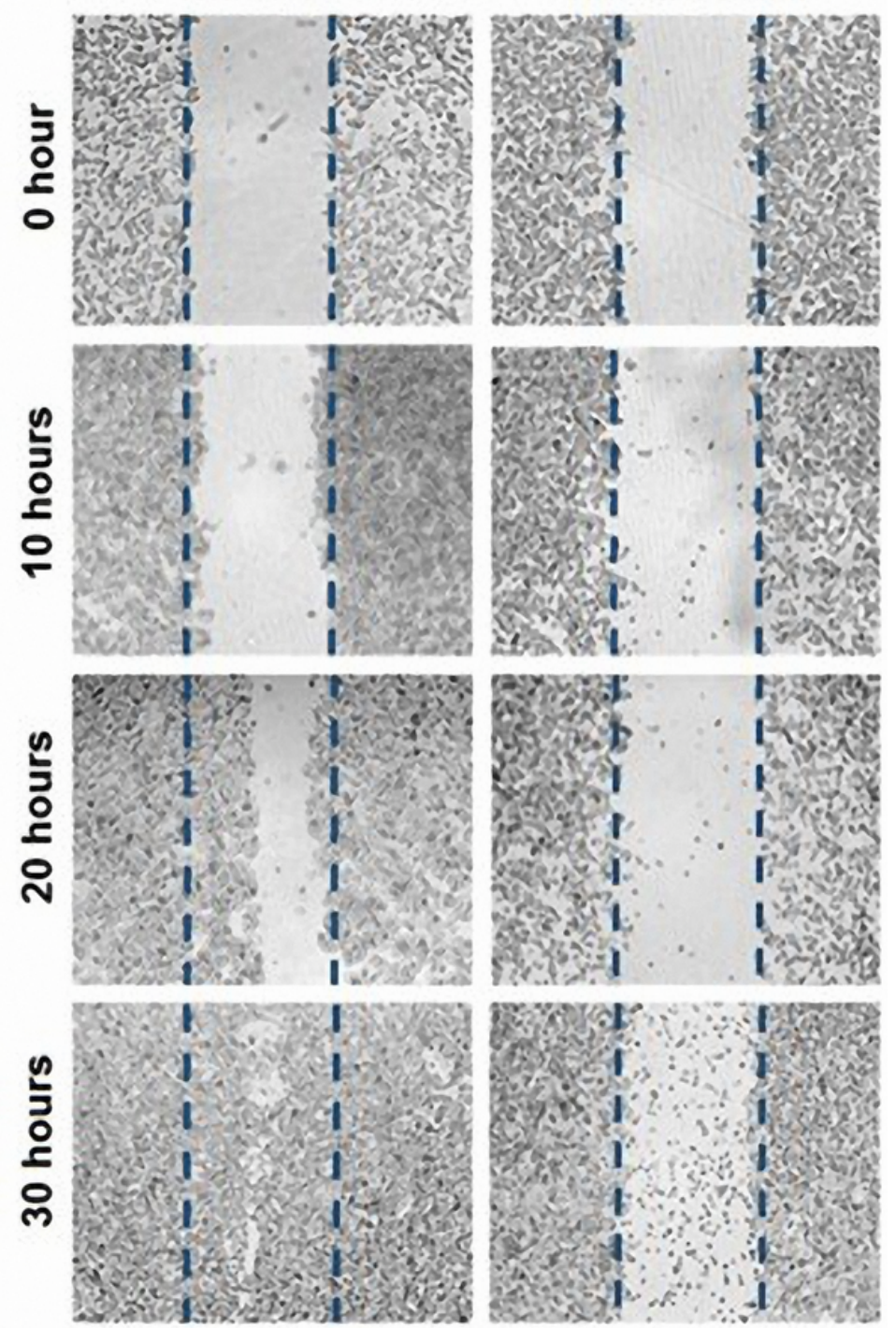

Figure 2

The migration and invasion of MDA-MB-231 and MDA-MB-468 breast cancer cells were evaluated with scratch wound-healing assay following transfection with miR-612. 

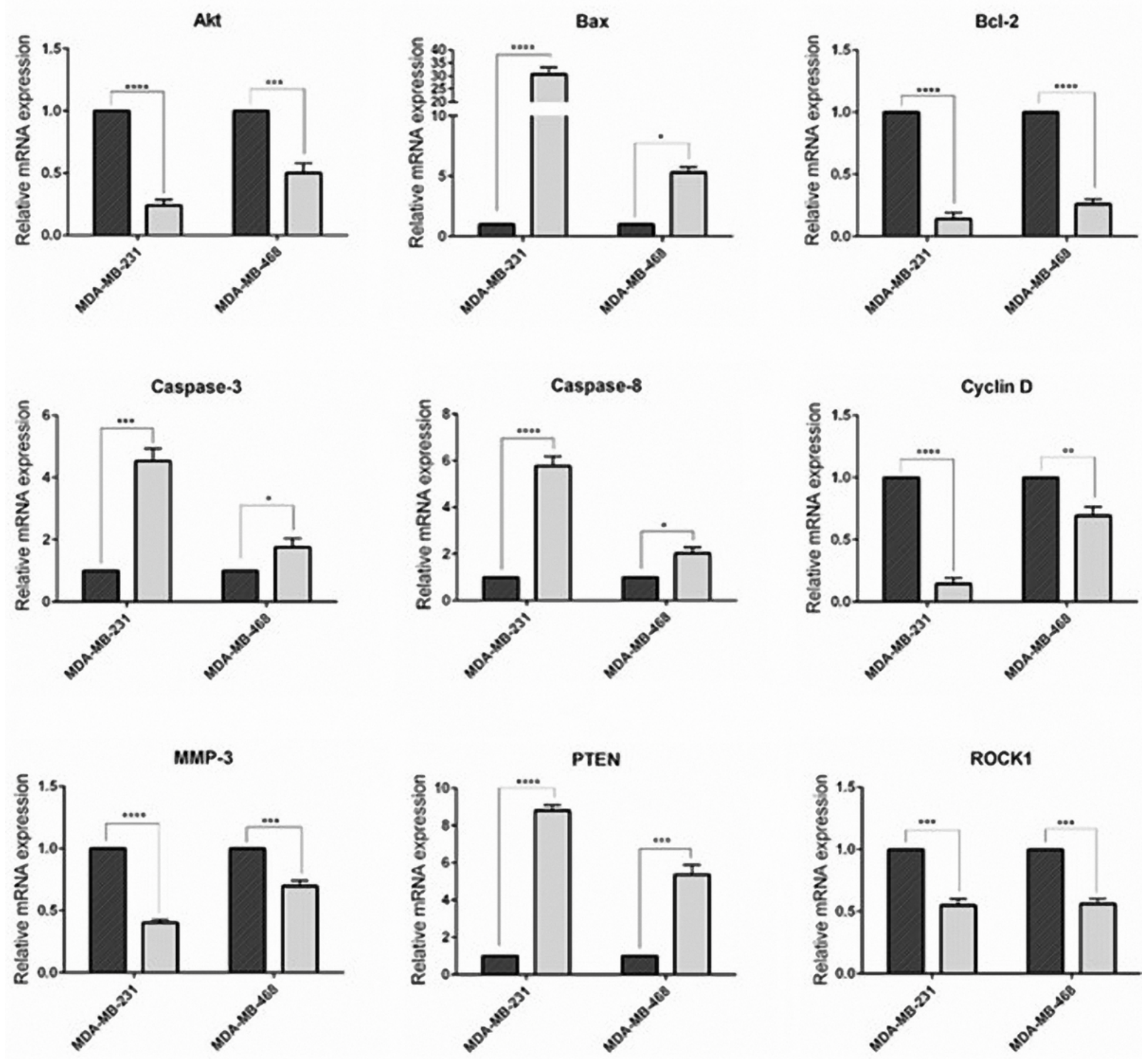

Figure 3

The real-time PCR analysis of Bax, Bcl2, Caspase3, Caspase8, Cyclin D, MMP3, PTEN, and ROCK1 genes expression in MDA-MB-231 and MDA-MB-468 breast cancer cells transfected with miR-612. 
MDA-MB-231

Control

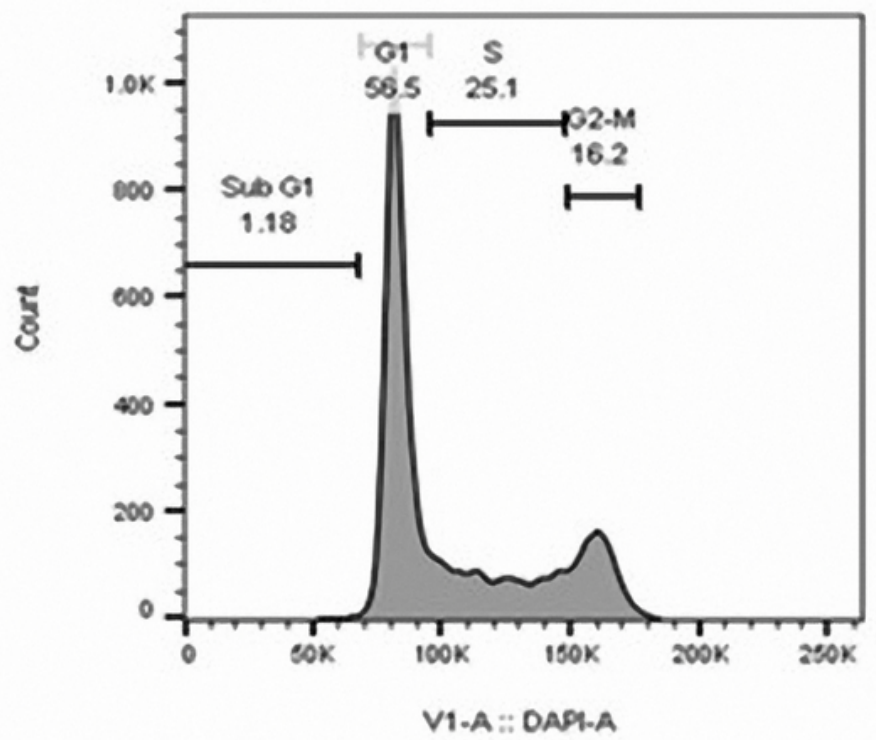

Transfected

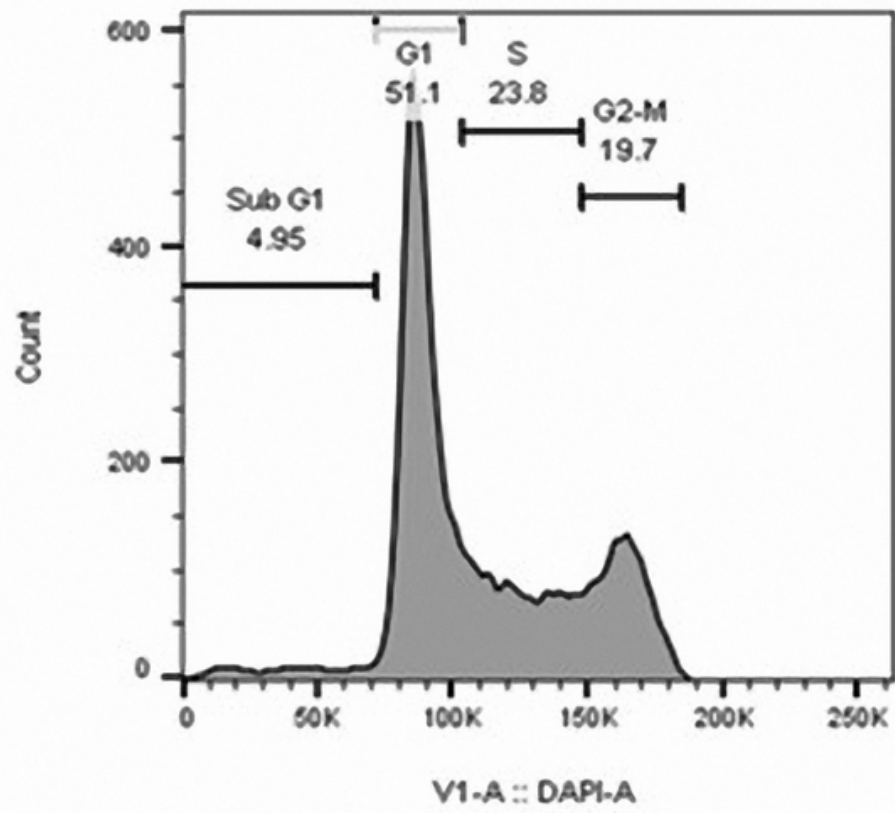

MDA-MB-468

Control

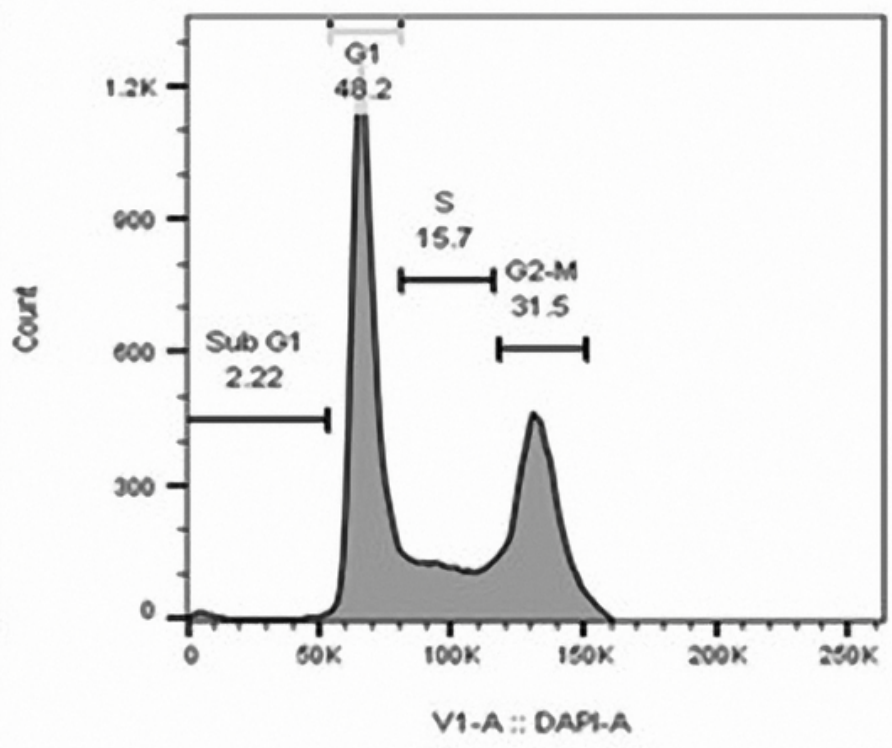

Transfected

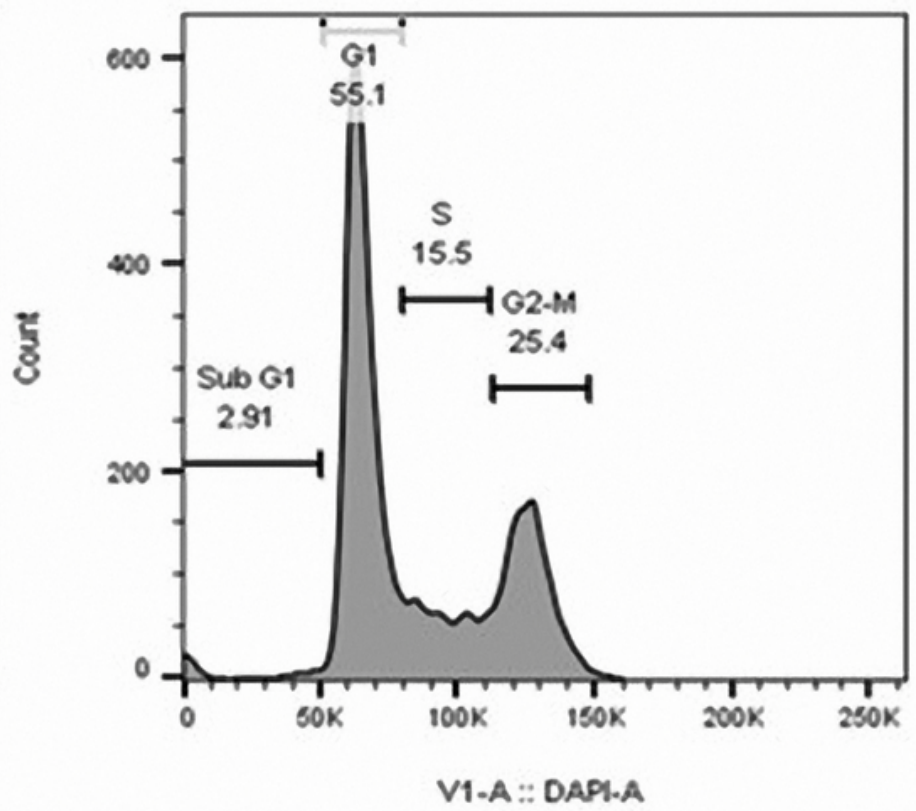

Figure 4

Evaluation of cell cycle by propidium iodide (PI) staining in MDA-MB-231 and MDA-MB-468 breast cancer cells transfected with miR-612. 
MDA-MB-231
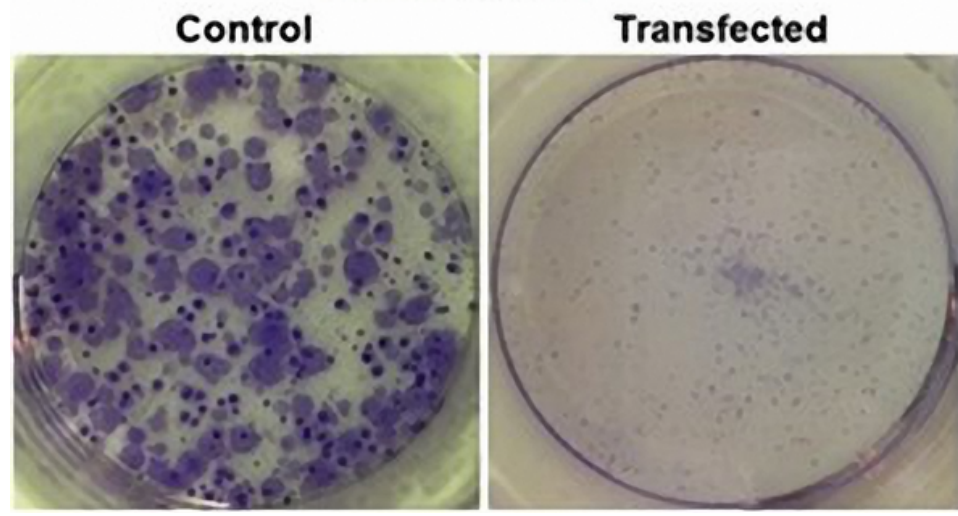

MDA-MB-468

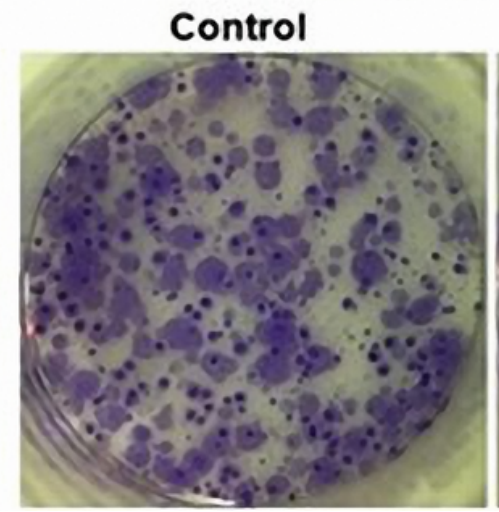

Transfected

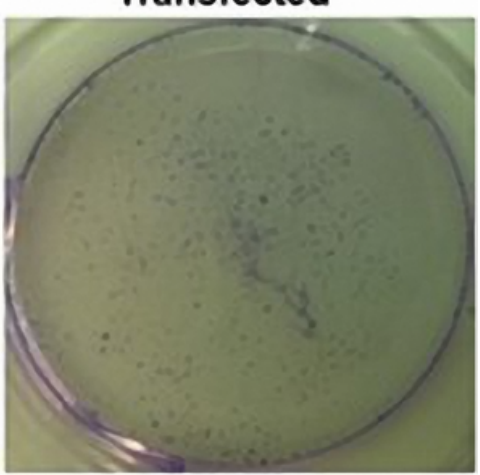

Figure 5

The inverted phase-contrast images from the colony formation by MDA-MB-231 and MDA-MB-468 breast cancer cells transfected with miR-612.

MDA-MB-231

Transfected

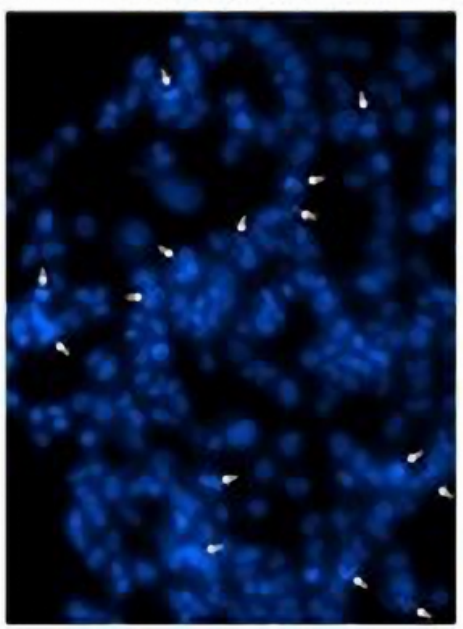

Control

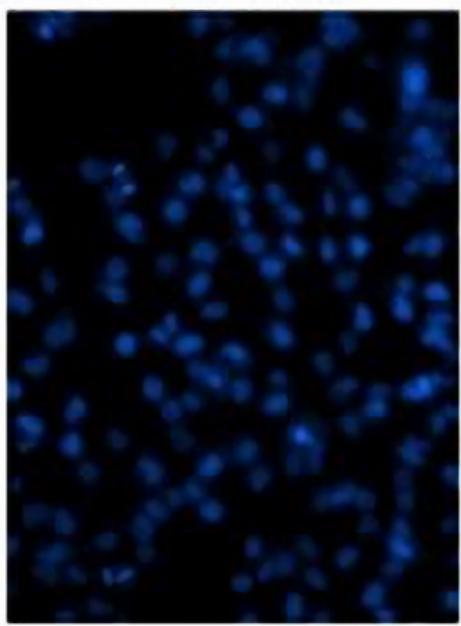

MDA-MB-468

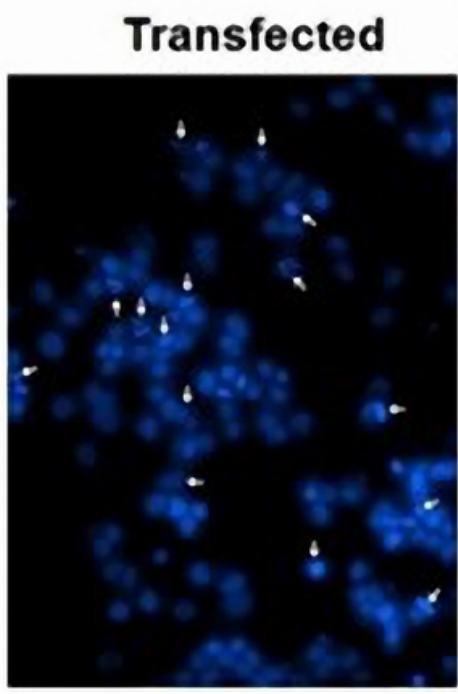

Control

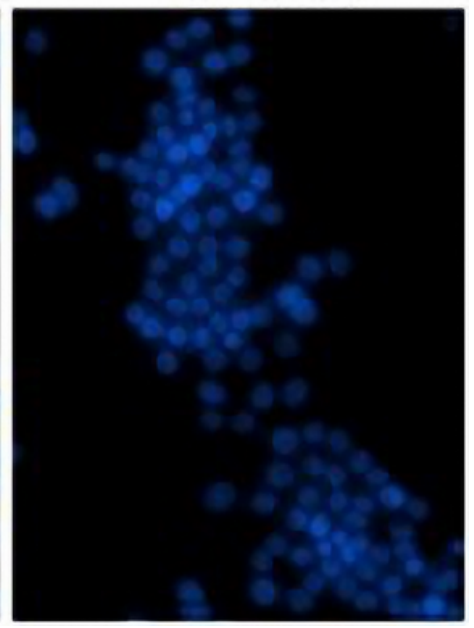

Figure 6

The qualifying of apoptosis by DAPI staining in MDA-MB-231 and MDA-MB-468 breast cancer cells transfected with miR-612. 
MDA-MB-231

Control unstain

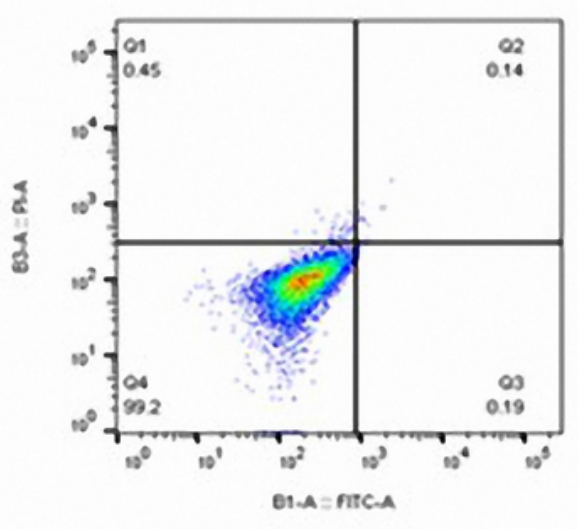

Control stain

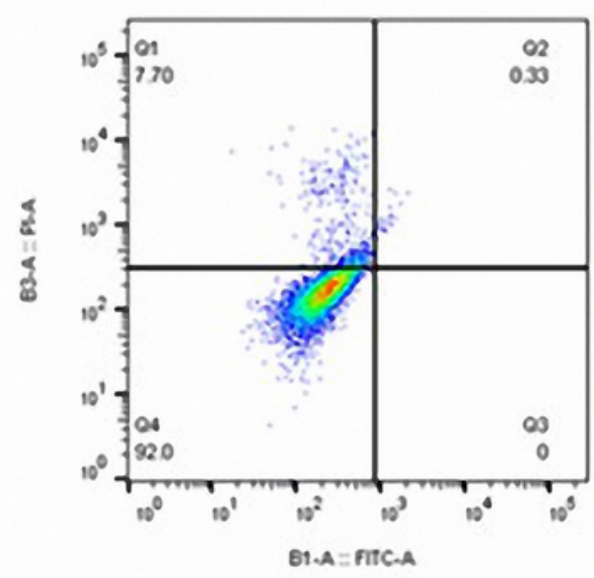

Transfected

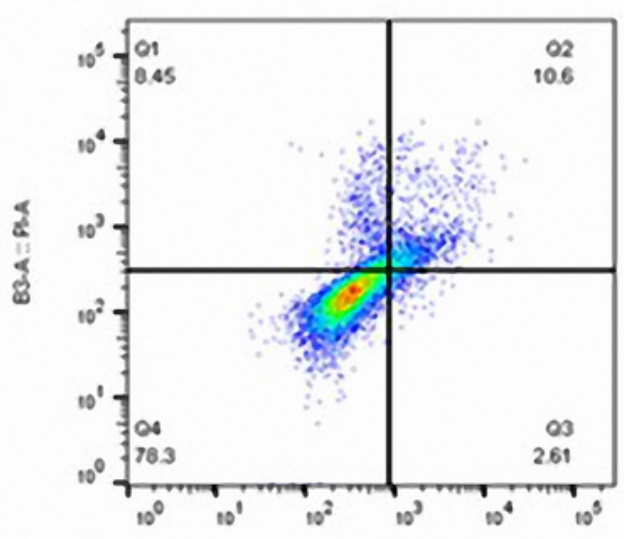

MDA-MB-468

Control unstain

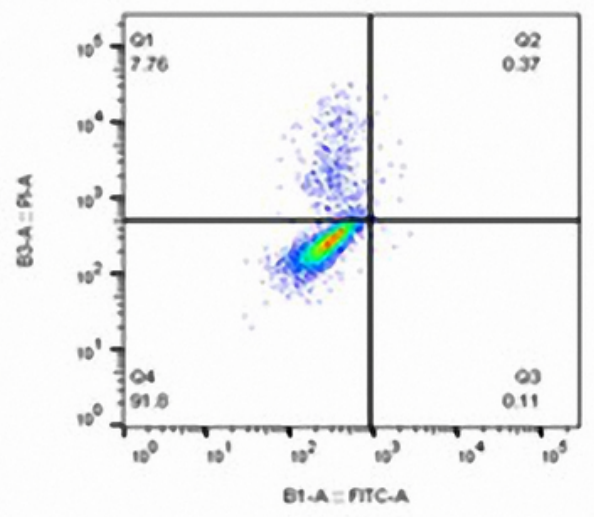

Control stain

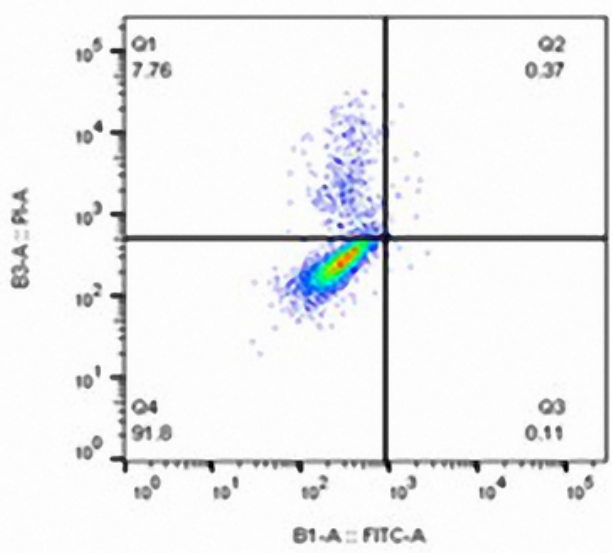

Transfected

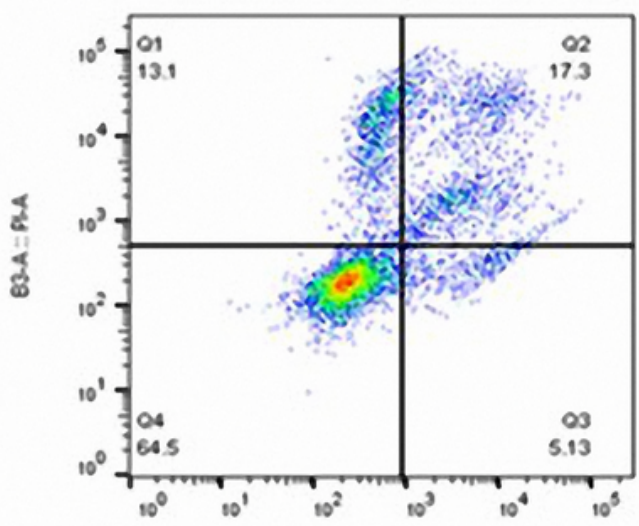

\section{Figure 7}

Quantification of apoptosis by annexin V-FITC/PI assay in MDA-MB-231 and MDA-MB-468 breast cancer cells transfected with miR-612. 


\section{MDA-MB-231}
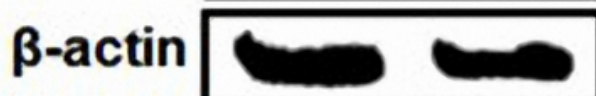

AKT
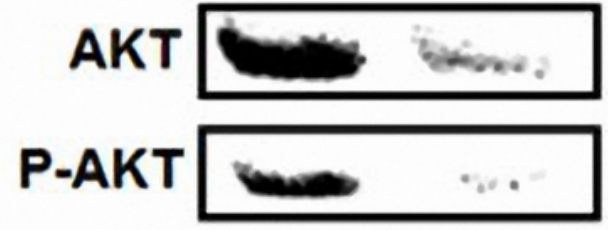

ERK
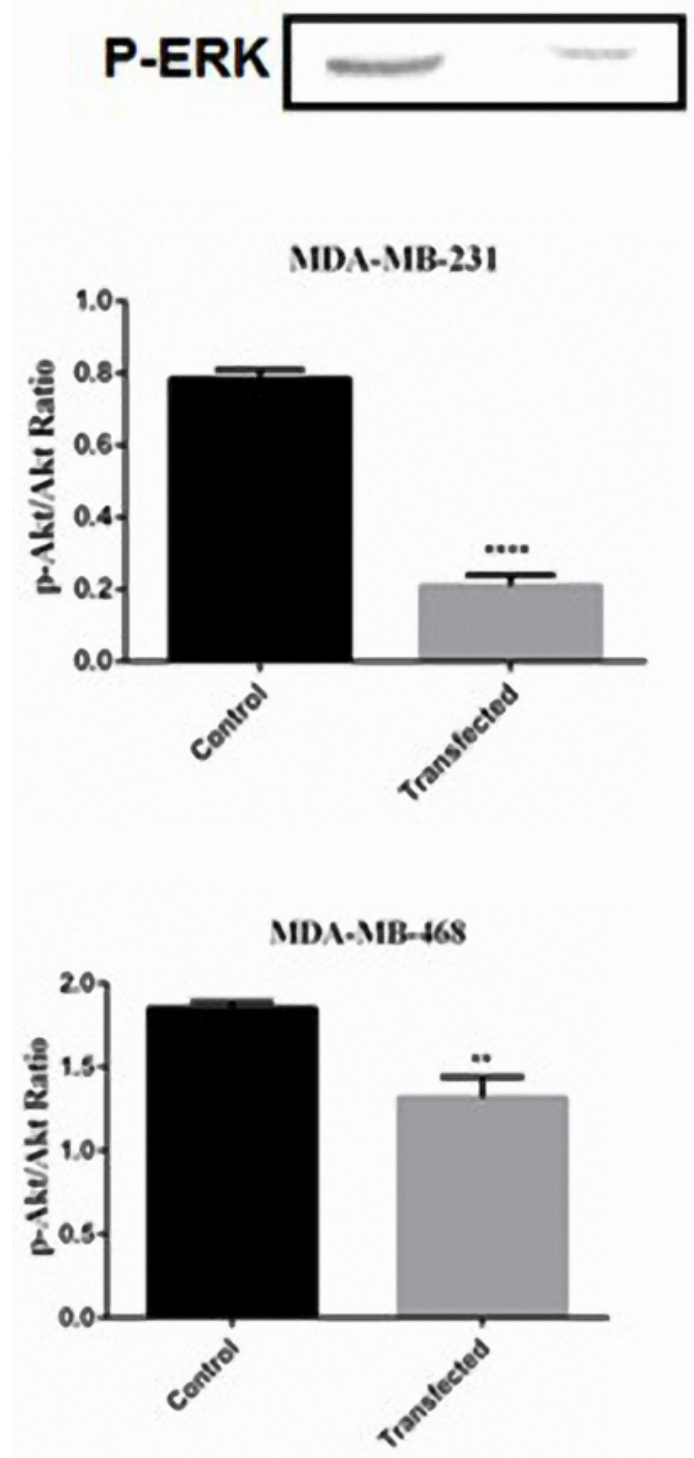

MDA-MB-468
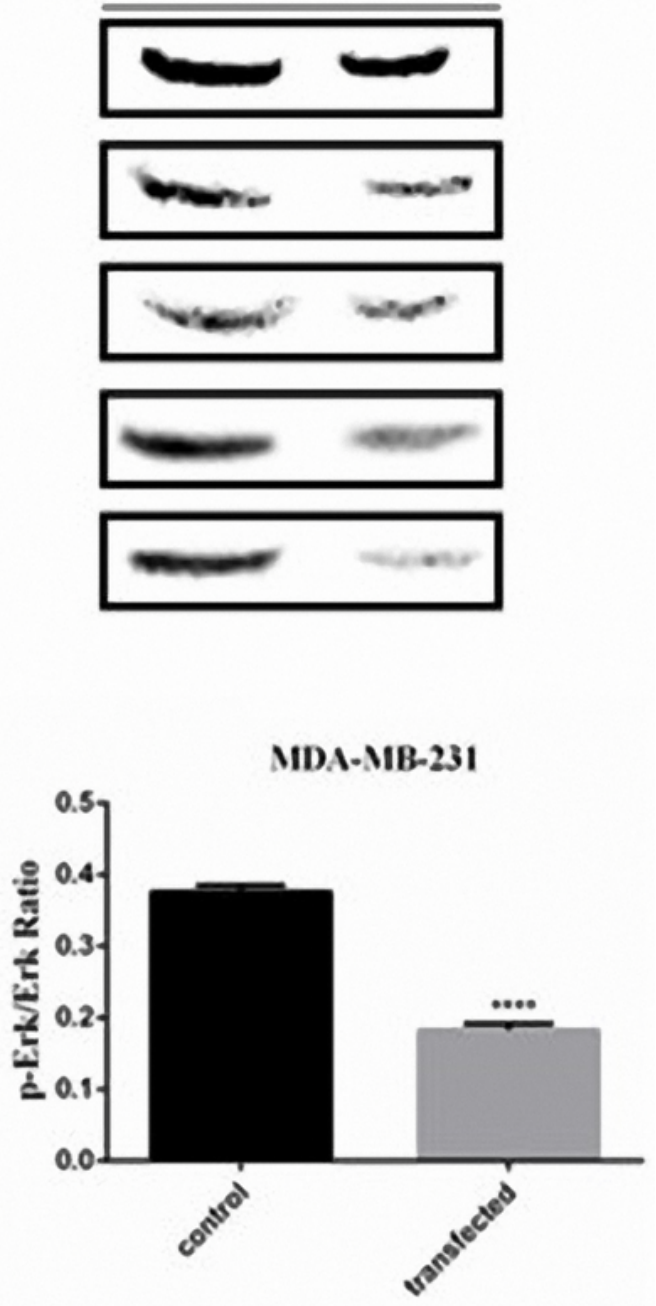

IDA-NIB-46S

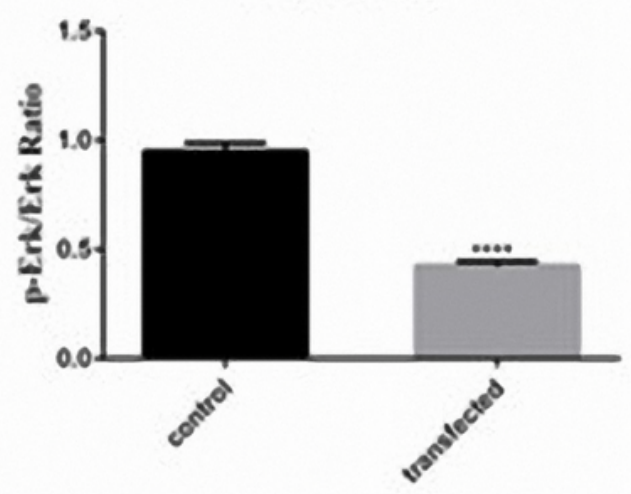

Figure 8

The western blot analysis of AKT, P-AKT, ERK, and P-ERK proteins levels in MDA-MB-231 and MDA-MB468 breast cancer cells transfected with miR-612. 